\title{
Níveis de Hormônios Tireoideanos em Pacientes com Dissecção Aórtica. Comparação com Controles e Correlação com a Porcentagem de Área da Camada Média Composta por Depósitos Mixóides
}

\author{
Paulo Sampaio Gutierrez, Maria Adelaide Albergaria Pereira, Regina Célia Martins Oliveira, \\ Noedir Antonio Groppo Stolf, Maria de Lourdes Higuchi
}

São Paulo, SP

\begin{abstract}
Objetivo - Pesquisar a ocorrência de disfunção clínica ou subclínica da tireóide em portadores de dissecção aórtica e analisar se há correlação entre os níveis séricos de hormônios relacionados à função tireoideana e ao conteúdo de material mixóide da média aórtica.

Métodos - Níveis séricos de triiodotironina (T3), tiroxina (T4) e hormônio estimulador da tireóide (TSH) foram dosados por métodos convencionais em 28 pacientes em pós-operatório de correção de dissecção aórtica; T4 livre foi medido em 20 deles. Os mesmos hormônios foram quantificados em 20 pacientes-controle pareados por sexo e idade. Os resultados foram comparados pelo teste de Mann-Whitney. A porcentagem da camada média da aorta ocupada por material mixóide foi medida em espécimes cirúrgicos de 25 pacientes e correlacionada aos níveis séricos de hormônios através do teste de Pearson. Estabeleceu-se o nível de significância como $p \leq 0,05$.
\end{abstract}

Resultados - Nos 20 pares nos quais as quantidades de hormônios foram comparadas, os valores médios de T3, T4, T4 livre e TSH foram 1,22ng/ml, 9,89mcg/dl, 1,18ng/dl e 5,45 microUi/ml nos casos e 1,15ng/ml, 8,57mcg/dl, 1,32ng/dl e 2,15microUi/ml nos controles. Nem tais diferenças nem a correlação entre a percentagem de conteúdo mixóide (média $=30 \%$ ) e os valores de T3, T4, T4 livre e TSH (médias- 1,22ng/ml, 9,44mcg/dl, 1,20ng/dl e 5,08 micro Ui/ml; $n=25)$ foram significantes.

Conclusão - Nossos dados sugerem que a dissecção da aorta; não têm relação com os níveis séricos de hormônios tireoideanos.

Palavras-chave: aneurismas dissecantes, aorta, hormônios tireóideos

Instituto do Coração do Hospital da FMUSP

Correspondência: Paulo Sampaio Gutierrez - Incor - Av. Dr. Eneas C. Aguiar, 44 Cep 05403-000 - São Paulo, SP - E-mail: anppaulo@incor.usp.br Recebido para publicação em 10/1/03

Aceito em 31/3/03
A dissecção da aorta consiste na delaminação de sua parede, em meio àtúnica média, no sentido longitudinal. Criase, portanto, uma falsa luz, paralela à verdadeira, com extensão variável (fig 1) ${ }^{1}$. Caso não tratada, apesar de relativamente rara, é doença com alta mortalidade. Sua incidência foi estimada em 5 a 29 casos/ milhão de população/ano ${ }^{2,3}$. Em várias condições, a dissecção aórtica se associa: hipertensão arterial sistêmica (a mais comum, encontrada em 70-90\% dos casos), síndrome de Marfan, síndrome de Hurler e traumatismo, incluindo-se manuseio cirúrgico da aorta ${ }^{1}$. Uma pequena porcentagem dos pacientes não tem nenhuma condição associada. A patogênese desta doença não está ainda elucidada. Muito embora a maioria dos pacientes com dissecção tenha hipertensão arterial, ela corresponde apenas a uma pequena porcentagem dos hipertensos. Presume-se que haja fraqueza da parede aórtica subjacente à dissecção, porém os fatores subjacentes a essa fraqueza não são bem conheci$\operatorname{dos}^{4}$. Ao exame histopatológico, encontra-se na camada média três achados principais: fragmentação das fibras elásticas; diminuição da população de células musculares lisas; e acúmulo de material mucóide, basofílico 5 . À somatória dos dois últimos achados foi dado o nome de necrose mediocística, embora não esteja comprovada a morte celular nesses locais, nem haja cistos verdadeiros (fig 2). A despeito de serem mais proeminentes em aortas com dissecção, as mesmas alterações podem ser vistas também como fenômenos secundários em diversas doenças aórticas, no envelhecimento, e mesmo, em pessoas hipertensas, mas sem dissecção ${ }^{5}$.

O material mucóide, aumentado nas dissecções da aorta, é um dos mais importantes componentes da camada média dessa artéria. Proteoglicanos, compostos por uma proteína com cadeias laterais de glicosaminoglicanos (uma família de açúcares de cadeia longa), ou glicosaminoglicanos por si próprios, como o hialuronan (ácidohialurônico), são as moléculas que dão aos tecidos essa característica 


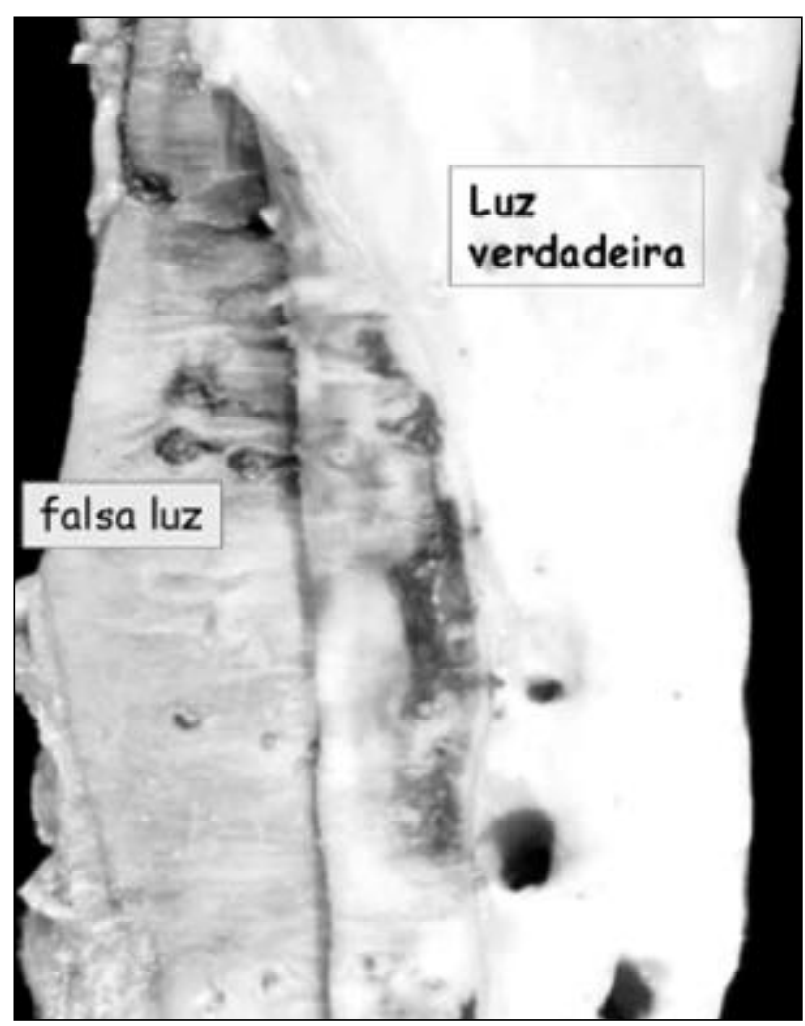

Fig. 1- Segmento de aorta humana apresentando dissecção, caracterizada pela delaminação da parede em duas porções, à altura da túnica média. Uma luz falsa é criada.

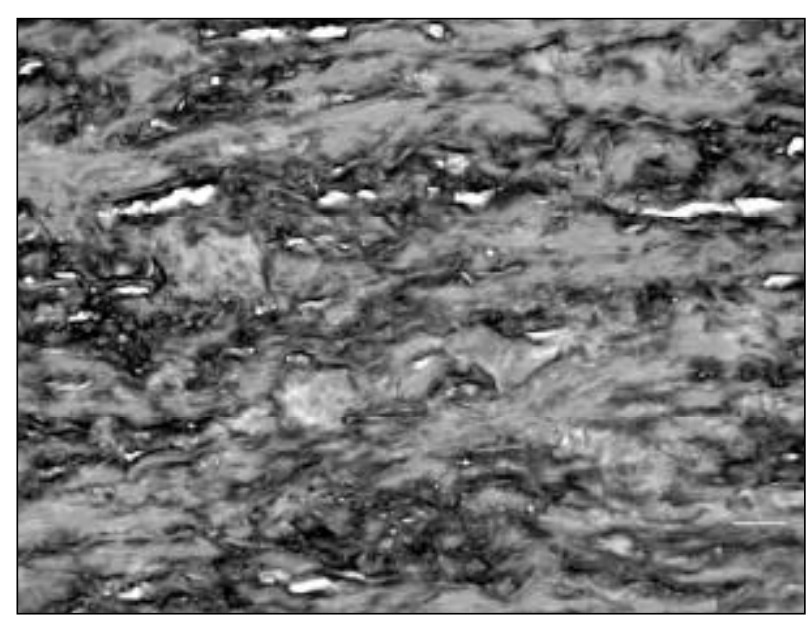

Fig. 2 - Corte histológico da túnica média da aorta humana com dissecção, corada pelo Alcian-blue para demonstrar os proteoglicanos, e contracorada com hematoxilina, em tom róseo. Aumento da objetiva: 40x. Barra (canto inferior direito) $=20 \mu \mathrm{m}$.

histológica ${ }^{6}$, também chamada de mixóide (myxos= mucus). Esse material é similar ao mixedema pretibial ou retroocular presente em alguns pacientes com doenças da tireóide.

Rosenmann e Yarom compararam os achados morfológicos nas glândulas tireóides de 101 casos de necrópsia de dissecção com outros 100 escolhidos dentro do mesmo universo, sem essa doença, mas pareados por idade, sexo, gravidade de aterosclerose, presença ou não de hipertensão e peso cardíaco. Constataram diferença estatisticamente significante: havia alterações anatomopatológicas marcantes e, possivelmente, provocadoras de hipotireoidismo em $22 \%$ dos casos de dissecção; incluindo-se lesões mais leves, a porcentagem chegou a $49 \%$ do total. Entre os controles, as porcentagens foram de $8 \%$ e $18 \%$, respectivamente ${ }^{7}$. No entanto, a avaliação clínico-laboratorial foi restrita a apenas um dos casos, no qual foi documentado hipotireoidismo ${ }^{7}$.

Esses dados trazem à tona uma possibilidade bastante interessante - a de que a delaminação aconteceria preferencialmente nos pacientes com hipertensão arterial sistêmica e afecções da tireóide. O objetivo deste estudo foi verificar se pacientes com essa doença têm associação com disfunção tireoídea clínica ou subclínica, enfocando tanto a relação entre o conteúdo mucóide na média aórtica e os níveis séricos de hormônios tireoideanos, quando comparando tais níveis com os de pacientes-controle sem doença aórtica.

\section{Métodos}

Foram investigados 28 pacientes ( 21 de sexo masculino) com diagnóstico comprovado de dissecção aórtica, desde que atingisse a aorta ascendente (tipo A pela classificação de Stanford $^{8}$ ou tipo I ou II pela classificação de DeBakey $^{9}$ ), e submetidos a tratamento cirúrgico. A idade variou de 37 a 76 anos (média 58, mediana 59). Dados clínicos desses pacientes são apresentados na tabela I.

Pacientes que haviam sido submetidos a cirurgia de revascularização do miocárdio com aortotomia, pareados com os casos de dissecção, de acordo com sexo e idade, entraram no estudo como controles.

Os níveis séricos de triiodotironina (T3), tiroxina (T4), T4 livre e de hormônio tireotrófico (TSH) foram quantificados nos casos e em 20 controles e por métodos convencionais (radioimunoensaio, quimioluminescência ou IRMA). Em oito pacientes não foi medido o T4 livre.

Cortes histológicos com $3 \mu \mathrm{m}$ de espessura da aorta de 25 pacientes, amostradas durante a cirurgia, foram corados pelo Alcian blue, que tinge em azul os glicosaminoglicanos, inclusive os que tomam parte das cadeias laterais de proteoglicanos. Para aumentar o contraste, os cortes foram contracorados com hematoxilina (fig 2). As lâminas foram examinadas em microscópio Leica acoplado a sistema de análise de imagens Quantimet, utilizando objetiva de 40x. Áreas azuis foram quantificadas por detecção, e a área total do corte foi medida através de delineamento manual. As quantificações foram realizadas em pelo menos 20 campos da tela; após o $20^{\circ}$, foram também abordados campos adicionais até que a espessura total da artéria fôsse completamente analisada. A porcentagem média de área ocupada por substância mixóide foi então calculada em cada aorta.

O programa SPSS para Windows 6.0 foi usado para o estudo estatístico. As taxas séricas de hormônios tireoideanos em casos e controles foram comparadas pelo teste de Mann-Whitney e a presença de hipertensão arterial sistêmica nesses dois grupos pelo teste exato de Fisher. Devido à ausência de controles para todos os casos, as análises se restringiram a 20 pacientes ( 14 com relação ao T4 livre). A correlação entre a porcentagem de conteúdo mucóide e os 


\begin{tabular}{|c|c|c|c|c|c|c|c|}
\hline $\begin{array}{l}\text { Número } \\
\text { do caso }\end{array}$ & Idade & Gênero & HAS & $\begin{array}{c}\text { Tempode } \\
\text { evolução* }\end{array}$ & $\begin{array}{c}\text { Região } \\
\text { dissecada }\end{array}$ & $\begin{array}{c}\text { Duração da } \\
\text { dissecção }\end{array}$ & Observações \\
\hline 1 & 37 & $\mathrm{~F}$ & Não & 1 ano & $A+D$ & 2 meses & Ectasia ânulo-aórtica \\
\hline 2 & 42 & M & Sim & 9 meses & A & Crônica & \\
\hline 3 & 43 & M & Sim & 1 ano & $A+D$ & $<1$ dia & \\
\hline 4 & 43 & M & Sim & 8 meses & $A+D$ & 3 dias & \\
\hline 5 & 45 & M & Sim & 4 anos & A & Crônica & Gota \\
\hline 6 & 46 & M & Sim & 5 meses & A & 10 dias & RM prévia; $\mathrm{Hbs} \mathrm{Ag}+$ \\
\hline 7 & 47 & M & Sim & 5 meses & A & $\sim 2$ semanas & \\
\hline 8 & 51 & $\mathrm{~F}$ & Sim & 1 ano & A & Crônica & Aneurisma aórtico prévio; dislipemia \\
\hline 9 & 53 & M & Sim & 11/3anos & $A+(A+D)$ & Acuda/ Crônica & \\
\hline 10 & 55 & M & Sim & 4 anos & $\mathrm{A}+\mathrm{D}$ & 2 dias & Obesidade \\
\hline 11 & 57 & M & Sim & $9 / 3 a n o s$ & $\mathrm{~A}+\mathrm{A}$ & $<1$ dia, Crônica & Redissecção; infarto do miocárdio prévio \\
\hline 12 & 58 & $\mathrm{~F}$ & Inc & 10 meses & A & Crônica & Doença da tireóide conhecida \\
\hline 13 & 59 & M & Sim & 6 meses & $A+D$ & $<1$ dia & RM prévia \\
\hline 14 & 60 & M & Sim & 1 ano & $\mathrm{A}+\mathrm{D}$ & Crônica & Adenocarcinoma gástrico \\
\hline 15 & 62 & $\mathrm{~F}$ & Sim & 14 anos & A & Crônica & Diabetes mellitus, obesidade \\
\hline 16 & 63 & $\mathrm{~F}$ & Sim & 4 meses & A & Crônica & Neoplasia uterina \\
\hline 17 & 64 & M & Sim & 3,5 anos & A & Crônica & Úlceras pépticas \\
\hline 18 & 65 & M & Sim & 12 anos & $\mathrm{A}+\mathrm{D}(?)$ & 1 dia & \\
\hline 19 & 65 & M & Inc & 11 anos & $\mathrm{A}+\mathrm{D}$ & 14 dias & \\
\hline 20 & 66 & $\mathrm{~F}$ & Sim & 12 meses & A & Crônica & Doença da tireóide conhecida; RM prévia \\
\hline 21 & 66 & M & Sim & 6 meses & $\mathrm{A}+\mathrm{D}$ & $<1 \mathrm{dia}$ & \\
\hline 22 & 67 & M & Não & 1 ano & A & $<1$ dia & \\
\hline 23 & 67 & M & Sim & 14 meses & A & Crônica & Ectasia ânulo-aórtica \\
\hline 24 & 70 & M & Sim & 2 anos & $A+D$ & 6 meses & \\
\hline 25 & 71 & $\mathrm{~F}$ & Sim & 10 meses & A & $<1$ dia & Dislipemia \\
\hline 26 & 71 & M & Sim & 1 ano & A (?) & $<1$ dia & Dislipemia; dissecção iatrogênica \\
\hline 27 & 74 & M & Não & 9 meses & A (?) & $<1$ dia & Dislipemia; dissecção iatrogênica \\
\hline 28 & 76 & M & Sim & 10 meses & A & Crônica & \\
\hline
\end{tabular}

níveis hormonais foi verificada através do teste de Pearson, em 25 casos, uma vez que nos outros três não foram retirados fragmentos da aorta durante a cirurgia. Para todos os testes, estabeleceu-se o nível de significância como $p \leq 0,05$.

\section{Resultados}

Tinham hipertensão arterial sistêmica 16 entre os 20 (80,0\%) pacientes com dissecção e 10 entre $14(71,4 \%)$ controles; informação não disponível nos prontuários de 6 deles. Assim sendo, não houve diferença quanto à proporção de hipertensos $(\mathrm{p}=0,69)$.

Dois dos casos e um controle referiam sofrer de doença da tireóide e tomavam medicação específica; um deles tinha baixo nível de TSH.

As taxas séricas de T3, T4, T4 livre e TSH encontramse na tabela II. Além dos pacientes mencionados, alterações hormonais compatíveis com hipertireoidismo (dosagem de T4 livre alta e de TSH baixa) estavam presentes em dois casos e em três controles. Níveis altos de TSH, sugestivos de hipotireoidismo, quer clínico (T4 livre baixo), quer subclínico (T4 livre normal), foram achados em dois pacientes de cada grupo e em um paciente com dissecção aórtica no qual o T4 livre não foi dosado. No conjunto, não houve diferença significante entre os dois grupos.

A tabela III e a fig. 3 apresentam a porcentagem de área ocupada por material mucóide no grupo com dissecção. Não houve correlação com os níveis hormonais.

\section{Discussão}

Embora controversas ${ }^{10}$, há evidências de que os depósitos associados às doenças tireoideanas possam não ser restritos às regiões pré-tibial e retroocular, mas possam ser mais dispersos ${ }^{11}$. Por isso, desde o período subseqüente à descrição por Gsell e Erdheim, na década de 1920, de aumento de material basofílico nas aortas com dissecção, trabalhos tentaram verificar possível relação entre as duas entidades. Kountz e Hempelmann encontraram grande percentual de casos de dissecção aórtica em pacientes submetidos à tireoidectomia como tratamento de hipertensão $\operatorname{arterial}^{12}$, então preconizado, mas Burchell não demonstrou associação entre essa doença arterial e tireoidopatia ${ }^{13}$. Mais recentemente, foi relatado caso de dissecção iatrogênica após angioplastia coronariana percutânea em paciente com mixedema ${ }^{14}$, porém uma série analisando 48 pacientes com hipotireoidismo clínico ou subclínico sugeriu que a evolução após esse procedimento não é diferente da de pessoas eutireoidéas ${ }^{15}$. Em 1994, Rosenmann e Yarom ${ }^{7}$ mostraram freqüência aumentada de lesões anatomopatológicas da tireóide em necrópsias de pacientes com dissecção aórtica, embora, na maior parte deles, sem qualquer avaliação clínica ou bioquímica da função dessa glândula. 


\begin{tabular}{|c|c|c|c|c|c|c|c|c|c|c|c|c|c|}
\hline \multirow[t]{2}{*}{ Caso } & \multirow[t]{2}{*}{ Gênero } & \multicolumn{2}{|c|}{ Idade } & \multicolumn{2}{|c|}{ HAS } & \multicolumn{2}{|c|}{ T3 (ng/ml) } & \multicolumn{2}{|c|}{$\mathrm{T} 4$ (mcg/dl) } & \multicolumn{2}{|c|}{ T4 livre (ng/dl) } & \multicolumn{2}{|c|}{$\mathrm{TSH}$ (microUi/ml) } \\
\hline & & DA & $\mathrm{C}$ & DA & $\mathrm{C}$ & $\mathrm{DA}$ & $\mathrm{C}$ & DA & $\mathrm{C}$ & DA & $\mathrm{C}$ & DA & $\mathrm{C}$ \\
\hline 5 & M & 45 & 45 & $\mathrm{~S}$ & $\mathrm{~S}$ & 1,5 & 1,9 & 11,0 & 9,8 & 1,6 & 1 & 2,3 & 1,4 \\
\hline 7 & M & 47 & 49 & S & $\mathrm{S}$ & 0,9 & 1,1 & 6,5 & 11,1 & 0,87 & 1,4 & 2,8 & 1 \\
\hline 9 & M & 53 & 54 & S & $S$ & 1,4 & 0,8 & 12,1 & 9,0 & 0,9 & 1,4 & 1,4 & 1,9 \\
\hline 10 & M & 55 & 55 & S & $\mathrm{S}$ & 1,7 & 0,9 & 12,1 & 9,9 & 1,9 & 1,9 & 0,5 & 0,9 \\
\hline 11 & M & 57 & 59 & S & $\mathrm{S}$ & 1,9 & 1,1 & 11,3 & 12,2 & 1,1 & 2,6 & 1,2 & 0,6 \\
\hline 12 & $\mathrm{~F}$ & $58 *$ & 57 & I & $\mathrm{S}$ & 1,1 & 1,4 & 7,4 & 8,9 & - & 1 & 2,2 & 11,1 \\
\hline 13 & M & 59 & 61 & $\mathrm{~S}$ & I & 0,9 & 0,8 & 8,1 & 8,6 & 0,6 & 1,1 & 6,3 & 0,5 \\
\hline 14 & M & 60 & 63 & $S$ & $S$ & 0,7 & 0,9 & 9,3 & 9,4 & 1,3 & 1,4 & 2,1 & 2,1 \\
\hline 15 & $\mathrm{~F}$ & 62 & $62 *$ & $S$ & I & 1,1 & 2,1 & 19,7 & 9,7 & 1,9 & 1,1 & 0,4 & 5,7 \\
\hline 16 & $\mathrm{~F}$ & 63 & 65 & $S$ & $\mathrm{~S}$ & 1,66 & 1,1 & 8,9 & 6,1 & 1,2 & 1,1 & 1,4 & 3,7 \\
\hline 17 & M & 64 & 64 & S & I & 1,6 & 0,9 & 9,3 & 6,9 & 1,2 & 1,2 & 0,8 & 2,6 \\
\hline 18 & M & 65 & 65 & S & $\mathrm{N}$ & 1,6 & 1 & 18,5 & 8 & - & 1,3 & 1 & 0,9 \\
\hline 19 & M & 65 & 65 & I & I & 1,1 & 0,9 & 7,6 & 7 & 1,2 & 1,5 & 2,8 & 1,3 \\
\hline 21 & M & 66 & 66 & $S$ & $\mathrm{~N}$ & 1,8 & 1,4 & 12,4 & 8 & 1,3 & 1 & 1,3 & 1 \\
\hline 22 & M & 67 & 68 & $\mathrm{~N}$ & $S$ & 1,2 & 1,3 & 10,2 & 8 & - & 1,2 & $<0,1$ & 0,7 \\
\hline 23 & M & 67 & 68 & $S$ & I & 0,9 & 1,6 & 9,1 & 9,1 & - & 1,4 & 3,1 & 0,5 \\
\hline 25 & $\mathrm{~F}$ & 71 & 71 & $\mathrm{~S}$ & I & 0,6 & 1,1 & 6,7 & 9,8 & 1,2 & 1,3 & 3 & 0,2 \\
\hline 26 & M & 71 & 70 & $S$ & $\mathrm{~S}$ & 1,1 & 0,9 & 7,7 & 7,5 & - & 1,2 & 2 & 1,8 \\
\hline 27 & M & 74 & 72 & $\mathrm{~N}$ & $\mathrm{~N}$ & 0,7 & 0,7 & $<2,5$ & 6,5 & 0,27 & 1 & 72,8 & 4,7 \\
\hline 28 & M & 76 & 73 & $\mathrm{~S}$ & $\mathrm{~N}$ & 1 & 1,1 & 7,5 & 5,9 & - & 1,2 & 1,5 & 0,6 \\
\hline Média & & 62,25 & 62,60 & & & 1,22 & 1,15 & 9,89 & 8,57 & 1,18 & 1,32 & 5,45 & 2,15 \\
\hline Mediana & & 63,5 & 64,5 & & & 1,1 & 1,1 & 9,2 & 8,75 & 1,2 & 1,2 & 1,75 & 1,15 \\
\hline Normal & & & & \multirow{2}{*}{\multicolumn{2}{|c|}{0,69}} & \multicolumn{2}{|c|}{$0,8-2,0$} & \multicolumn{2}{|c|}{$4,5-12,5$} & \multicolumn{2}{|c|}{$0,8-1,9$} & \multicolumn{2}{|c|}{$0,3-4,5$} \\
\hline $\mathrm{p}$ & & & & & & & 48 & & 0,30 & & & & 35 \\
\hline
\end{tabular}

\begin{tabular}{|c|c|c|c|c|c|}
\hline \multicolumn{6}{|c|}{$\begin{array}{l}\text { Tabela III - Níveis de hormônios tireoideanos e porcentagem da } \\
\text { camada média da aorta ocupada por material mixóide }\end{array}$} \\
\hline Caso & $\begin{array}{c}\mathrm{T} 3 \\
(\mathrm{ng} / \mathrm{ml})\end{array}$ & $\begin{array}{c}\mathrm{T} 4 \\
(\mathrm{mcg} / \mathrm{dl})\end{array}$ & $\begin{array}{l}\text { T4 livre } \\
\text { (ng/dl) }\end{array}$ & $\begin{array}{c}\text { TSH } \\
\text { (microUi/ml) }\end{array}$ & \% mixóide \\
\hline 1 & 1,5 & 11,4 & 1,5 & 3,0 & 37 \\
\hline 2 & 1,3 & 9,2 & 1,4 & 0,5 & 28 \\
\hline 3 & 0,8 & 13,7 & - & 4,3 & 35 \\
\hline 4 & 1,5 & 10,0 & 1,3 & 1,9 & 25 \\
\hline 5 & 1,5 & 11,0 & 1,6 & 2,3 & 15 \\
\hline 6 & 0,9 & 7,3 & 1,4 & 2,4 & 32 \\
\hline 7 & 0,9 & 6,5 & 0,9 & 2,8 & 26 \\
\hline 8 & 1,1 & 6,7 & - & 3,5 & 28 \\
\hline 9 & 1,4 & 12,1 & 0,9 & 1,4 & 40 \\
\hline 11 & 1,9 & 11,3 & 1,1 & 1,8 & 29 \\
\hline 12 & 1,1 & 7,4 & - & 2,2 & 37 \\
\hline 13 & 0,9 & 8,1 & 0,6 & 6,3 & 22 \\
\hline 14 & 0,7 & 9,3 & 1,3 & 2,1 & 23 \\
\hline 16 & 1,7 & 8,9 & 1,2 & 1,4 & 23 \\
\hline 18 & 1,6 & 18,5 & - & 1,0 & 29 \\
\hline 19 & 1,1 & 7,6 & 1,2 & 2,8 & 24 \\
\hline 20 & 1,9 & 10,8 & 1,6 & 0,2 & 31 \\
\hline 21 & 1,8 & 12,4 & 1,3 & 1,3 & 25 \\
\hline 22 & 1,2 & 10,2 & - & $<0,1^{\S}$ & 28 \\
\hline 23 & 0,9 & 9,1 & - & 3,1 & 22 \\
\hline 24 & 1,0 & 9,1 & 1,6 & 3,9 & 31 \\
\hline 25 & 0,6 & 6,7 & 1,2 & 3 & 31 \\
\hline 26 & 1,1 & 7,7 & - & 2,0 & 57 \\
\hline 27 & 0,7 & $<2,5^{*}$ & 0,27 & 72,8 & 40 \\
\hline 28 & 1,0 & 7,5 & - & 1,5 & 33 \\
\hline$r$ & $-0,15$ & $-0,14$ & $-0,27$ & 0,23 & \\
\hline$p$ & 0,47 & 0,49 & 0,30 & 0,27 & \\
\hline \multicolumn{6}{|c|}{$\begin{array}{l}\text { T3 - triiodotironina; T4 - tirosina; TSH - hormônio tireotrófico * - para } \\
\text { cálculos estatísticos, o valor foi computado como } 2,4 ; \S \text {-para cálculos es- } \\
\text { tatísticos, o valor foi computado como } 0,09 ; \mathrm{r} \text { - coeficientes de correlação } \\
\text { entre \% mixóide e cada nível de hormônio tireoideano. }\end{array}$} \\
\hline
\end{tabular}

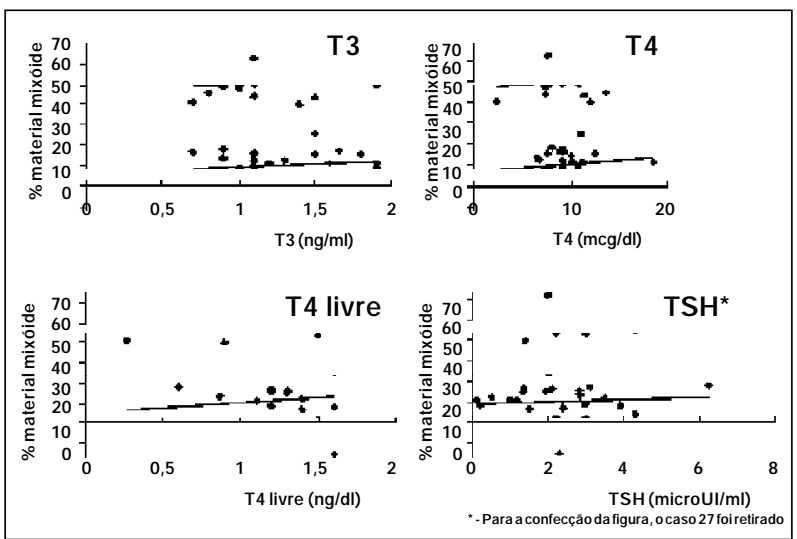

Fig. 3 - Relação entre taxas séricas de hormônios tireoideanos e área de material mixóide na camada média de aortas com dissecção.

Ainda que os glicosaminoglicanos, tomando ou não parte de cadeias de proteoglicanos, provavelmente, dão aos depósitos mixóides esse aspecto histológico, tanto na aorta quanto nos depósitos decorrentes de disfunção tireoideana, os tipos de cadeia polissacarídicas envolvidas podem não ser os mesmos. Há indícios experimentais de que hialuronan ou decorina, um pequeno proteoglicano sulfatado, esteja ligado aos depósitos relacionados à tireóide ${ }^{16-19}$. Já quanto às dissecções aórticas, análises anteriores feitas por nós foram inconclusivas, sugerindo que nem esses nem outros compostos pesquisados estejam presentes nos cistos mucói$\operatorname{des}^{20}$. Apesar dessas discrepâncias, não se pode descartar totalmente a eventual existência de vínculo entre eles, já 
que as naturezas exatas desses acúmulos não foram totalmente esclarecidas.

Vale ainda notar que, enquanto os distúrbios de tireóide acometem mais as mulheres, o oposto acontece nas dissecções aórticas (razão de 3:1 dentre homens e mulheres ${ }^{21}$, aproximadamente a mesma presente em nossos casos). Isso, por si só, fala contra a eventual relação entre as duas moléstias.

Realizamos o presente estudo não só devido à presença de depósito mucóide nas duas condições, mas também pela controvérsia em relação à possível relação entre elas. Restringimos os casos àqueles em pós-operatório tardio, para que estivessem clinicamente estáveis quanto à doença vascular, pois as taxas hormonais podem estar alteradas em pacientes em estado crítico. De acordo com critérios utilizados na literatura ${ }^{22}$, a função tireoideana foi avaliada pelos níveis séricos de T3, T4, T4 livre e, principalmente, de TSH.

Não houve diferença significativa entre os pacientes com dissecção e os controles, pareados por sexo e idade e também submetidos a aortotomia (durante a revascularização do miocárdio) nem quanto à presença de hiper ou hipotireoidismo, nem quanto às dosagens hormonais. Também não esteve presente correlação entre os níveis hormonais e a quantificação morfométrica de material mucóide na camada média das aortas com dissecção. Assim, nossos dados indicam não haver associação entre dissecções aórticas e a alterações funcionais da tireóide.

Quanto aos limites do estudo, poderia ter ocorrido interferência nos resultados se houvesse distúrbios da tireóide secundários a isquemia determinada pela dissecção aórtica. Entretanto, a isquemia não figura como fator relevante causador de doença dessa glândula. Por outro lado, alguns pacientes estavam em pós-operatório bastante tardio (chegando a anos); modificações na função tireoideana poderiam ter acontecido nesse período, ainda que sem relação com a delaminação da aorta. No entanto, tais possibilidades teriam maior implicação apenas se os resultados tivessem mostrado diferença entre os grupos ou influência dos hormônios no conteúdo mixóide.

\section{Agradecimentos}

À Adriana Psota e Solange Aparecida Consorte pelo apoio técnico; aos Drs. Fábio Fernandes, Paulo M. P. Fernandes, Roberto A.P. Mota e Débora S. Valejo pela ajuda na inclusão de pacientes no estudo, e à Fundação de Amparo à Pesquisa do Estado de São Paulo (FAPESP), projeto número 97/02923-4 pelo auxílio recebido.

\section{Referências}

1. Roberts WC. Aortic dissection: anatomy, consequences, and causes. Am Heart J 1982; 101: 195-214.

2. Fuster V, Halperin JL. Aortic dissection: a medical perspective. J Card Surg 1994; 9: 713-28.

3. Meszaros I, Morocz J, Szlavi J, Schmidt J, Tornoci L, Nagy L, Szep L. Epidemiology and clinicopathology of aortic dissection. Chest 2000; 117:1271-8.

4. Wilson SK, Hutchins GM. Aortic dissecting aneurysms. Causative factors in 204 subjects. Arch Pathol Lab Med 1982; 106: 175-80.

5. Schlatmann TJM, Becker AE. Pathogenesis of dissecting aneurysm of aorta: comparative histopathologic study of significance of medial changes. Am J Cardiol 1977; 39: 21-6.

6. Scott J. Proteoglycan histochemistry - a valuable tool for connective tissue biochemists. Coll Relat Res 1985; 5: 541-75.

7. Rosenmann E, Yarom R. Dissecting aneurysm of the aorta and hypothyroidism Isr J Med Sci 1994; 30: 510-3.

8. Daily PO, Trueblood W, Stinson EB, Wuerflein RD, Shumway NE (1970) Management of acute aortic dissections. Ann Thorac Surg 10: 237-47.

9. DeBakey ME, Henly WS, Cooley DA, Morris GC, Crawford FS, Beall AC Jr. Surgical management of dissecting aneurysms of the aorta. J Thorac Cardiovasc Surg 1965; 49: 130-48.

10. Peacey SR, Flemming L, Messenger A, Weetman AP. Is Graves' dermopathy a generalized disorder? Thyroid 1996; 6: 41-5.

11. Wortsman J, Dietrich J, Traycoff RB, Stone S. Preradial myxedema in thyroid disease. Arch Dermatol 1981; 117: 635-8.

12. Kountz WB, Hempelmann LH. Chromatrophic degeneration and rupture of the aorta following thyroidectomy in cases of hypertension. Am Heart J 1940; 20: 599-610.
13. Burchell HB. Aortic dissection (dissecting hematoma; dissecting aneurysm of the aorta. Circulation 1955; 12: 1068-74.

14. Okamoto R, Makino K, Saito K, et al. Aorto-coronary dissection during angioplasty in a patient with myxedema. Jpn Circ J 2000; 64: 316-20.

15. Mantzoros CS, Evagelopoulou K, Moses AC. Outcome of percutaneous transluminal coronary angioplasty in patients with subclinical hypothyroidism. Thyroid $1995 ; 5: 383-7$

16. Shishiba Y, Yanagishita M, Hascall VC. Effect of thyroid hormone deficiency on proteoglycan synthesis by human skin fibroblast cultures. Connect Tissue Res 1988; 17: 119-35.

17. Shishiba Y, Takeuchi Y, Yokoi N, Ozawa Y, Shimizu T. Thyroid hormone excess stimulates the synthesis of proteoglycan in human skin fibroblasts in culture. Acta Endocrinol (Copenh) 1990; 123: 541-9.

18. Sisson JC. Hyaluronic acid in localized myxedema. J Clin Endocrinol Metab 1968; 28: 433-6.

19. Imai $Y$, Odajima R, Inoue $Y$, Shishiba Y. Effect of growth factors on hyaluronan and proteoglycan synthesis by retroocular tissue fibroblasts of Graves' ophthalmopathy in culture. Acta Endocrinol (Copenh) 1992; 126: 541-52.

20. Gutierrez PS, Reis MM, Aiello VD, Higuchi ML, Stolf NAG, Lopes EA. Distribution of hyaluronan and dermatan/chondroitin sulphate proteoglycans in human aortic dissection. Connect Tis Res 1998; 37(3-4): 151-61.

21. DeSanctis RW, Doroghazi RM, Austen WG, Buckley MJ. Aortic dissection. N Engl J Med 1987; 317: 1060-7.

22. Weetman AP. Hypothyroidism: screening and subclinical disease. Br Med J 1997; 314 (7088): 1175-8. 